\title{
Author Correction: Liver Transplantation for Hepatocellular Carcinoma: Malatya Experience and Proposals for Expanded Criteria
}

\begin{abstract}
Volkan Ince ${ }^{1} \cdot$ Sami Akbulut ${ }^{1} \cdot$ Emrah Otan ${ }^{1} \cdot$ Veysel Ersan ${ }^{1} \cdot$ Serdar Karakas $^{1} \cdot$ Tolga Tevfik Sahin $^{1} \cdot$ Brian I Carr $^{1}$. Adil Baskiran ${ }^{1}$ - Emine Samdanci ${ }^{2}$ - Harika Gozukara Bag ${ }^{3}$. Cemalettin Koc ${ }^{1}$ - Sertac Usta ${ }^{1}$. Fatih Ozdemir ${ }^{1}$. Bora Barut ${ }^{1} \cdot$ Fatih Gonultas ${ }^{1}$ - Baris Sarici ${ }^{1} \cdot$ Koray Kutluturk ${ }^{1} \cdot$ Murat Sait Dogan ${ }^{1}$. Dincer Ozgor ${ }^{1}$. Mustafa Dikilitas $^{4} \cdot$ Murat Harputluoglu $^{5} \cdot$ Murat Aladag $^{5} \cdot$ Ramazan Kutlu $^{6} \cdot$ Ilknur Varol $^{7} \cdot$ Abuzer Dirican $^{1}$. Cemalettin Aydin ${ }^{1}$. Burak Isik ${ }^{1}$. Cengiz Ara ${ }^{1}$. Cuneyt Kayaalp ${ }^{1} \cdot$ Sukru Emre ${ }^{1}$. Sezai Yilmaz ${ }^{1}$
\end{abstract}

Published online: 8 July 2020

(C) Springer Science+Business Media, LLC, part of Springer Nature 2020

Author Correction: Journal of Gastrointestinal Cancer. https://doi.org/10.1007/s12029-020-00424-w

The original version of this article unfortunately contained a mistake in the author group section. The correct name of the second author is "Sami Akbulut."

The original article has been corrected.

Publisher's Note Springer Nature remains neutral with regard to jurisdictional claims in published maps and institutional affiliations.

The online version of the original article can be found at https://doi.org/ 10.1007/s12029-020-00424-w

Volkan Ince

volkanince@outlook.com

1 Department of Surgery, Liver Transplantation Institute, Inonu University, 44315 Malatya, Turkey

2 Department of Pathology, Medical School, Inonu University, Malatya, Turkey

3 Department of Biostatistics, Medical School, Inonu University, Malatya, Turkey

4 Department of Medical Oncology, Medical School, Inonu University, Malatya, Turkey

5 Department of Gastroenterology, Medical School, Inonu University, Malatya, Turkey

6 Department of Radiology, Medical School, Inonu University, Malatya, Turkey

7 Department of Pediatric Gastroenterolgy, Medical School, Inonu University, Malatya, Turkey 